\title{
Access to precision medicine in Thailand: a comparative study
}

\author{
Nisita Jirawutkornkul \\ Department of Social and Administrative Pharmacy, \\ Faculty of Pharmaceutical Sciences, Chulalongkorn University, \\ Bangkok, Thailand and \\ Pharmacy Department, Somdech Phra Debaratana Medical Center, \\ Faculty of Medicine Ramathibodi Hospital, Mahidol University, \\ Bangkok, Thailand, and \\ Chanthawat Patikorn and Puree Anantachoti \\ Department of Social and Administrative Pharmacy, \\ Faculty of Pharmaceutical Sciences, Chulalongkorn University, \\ Bangkok, Thailand
}

\begin{abstract}
Purpose - This study explored health insurance coverage of genetic testing and potential factors associated with precision medicine (PM) reimbursement in Thailand.

Design/methodology/approach - The study employed a targeted review method. Thirteen PMs were selected to represent four PM categories: targeted cancer therapy candidate, prediction of adverse drug reactions (ADRs), dose adjustment and cancer risk prediction. Content analysis was performed to compare access to PMs among three health insurance schemes in Thailand. The primary outcome of the study was evaluating PM test reimbursement status. Secondary outcomes included clinical practice guidelines, PMs statement in FDA-approved leaflet and economic evaluation.

Findings - Civil Servant Medical Benefits Scheme (CSMBS) provided more generous access to PM than Universal Coverage Scheme (UCS) and Social Security Scheme (SSS). Evidence of economic evaluations likely impacted the reimbursement decisions of SSS and UCS, while the information provided in FDA-approved leaflets seemed to impact the reimbursement decisions of CSMBS. Three health insurance schemes provided adequate access to PM tests for some cancer-targeted therapies, while gaps existed for access to PM tests for serious ADRs prevention, dose adjustment and cancer risk prediction.

Originality/value - This was the first study to explore the situation of access to PMs in Thailand. The evidence alerts public health insurance schemes to reconsider access to PMs. Development of health technology assessment guidelines for PM test reimbursement decisions should be prioritized.
\end{abstract}

Keywords Precision medicine, Genetic test, Access, Reimbursement, Thailand

Paper type Review

\section{Introduction}

Precision medicine (PM) is an approach to accurately select treatments or preventive measures based on the individual patient's genetic information. The human genome project

(C) Nisita Jirawutkornkul, Chanthawat Patikorn and Puree Anantachoti. Published in Journal of Health Research. Published by Emerald Publishing Limited. This article is published under the Creative Commons Attribution (CC BY 4.0) licence. Anyone may reproduce, distribute, translate and create derivative works of this article (for both commercial and non-commercial purposes), subject to full attribution to the original publication and authors. The full terms of this licence may be seen at http:// creativecommons.org/licences/by/4.0/legalcode

This study was funded by the CU Graduate School Thesis Grant of Chulalongkorn University Scholarship, Bangkok, Thailand. The funder had no role in any stage of conducting this study. The authors would like to thank Mr. Kan Yodinlom and Mr. Krit Yodinlom for proofreading.
Access to precision medicine in

Thailand

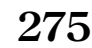

Received 15 April 2020 Revised 15 June 2020 Accepted 8 July 2020 
JHR

36,2

was first initiated in 1990 [1]. Since then, the knowledge in this field has greatly expanded. The Precision Medicine Coalition reported that the market authorization of genetic testing has sharply increased during the past decade [2]. As of 2019, there were more than 187 biomarkers for 377 companion drug items registered with the US FDA [3, 4]. Although knowledge about PM has been very well established for years, the adoption of PMs in clinical practice is still limited in many countries [5, 6].

Unlike their companion drugs, PM testing did not have a clear health technology assessment (HTA) framework for reimbursement decisions. In 2009, Meckley and Neumann explored factors affecting the reimbursement of six PMs in four public and private health insurers in the United States and the National Health Service of the United Kingdom. They found that the strength of clinical evidence synergized with the availability of clinical guidelines was a strong predictor of PM reimbursement decisions. On the contrary, types of PM test's regulatory and cost-effectiveness analysis were not associated with the reimbursement decision [7].

Chong et al. described the adoption of PMs among four Southeast Asian countries using five proxy PMs. They found that the countries did not have 1) a national strategic plan, 2) a comprehensive PM legislation, 3) a PM legal framework, and 4) PM data management system. Although these countries had an official HTA body, they did not have PM testspecific HTA guidelines [8].

In Thailand, neonatal screening for congenital hypothyroidism, phenylketonuria and thalassemia was initiated in 1992-1993 [9-11]. Presently, there are several ongoing PM research projects potentially applicable for targeted cancer drug selection, cancer risk prediction, rare diseases identification, severe adverse drug event prevention and drug metabolite prediction [12-15]. The majority of the genetic tests were provided free under research studies or as an ad hoc project. In 2013, the Health Intervention and Technology Assessment Program (HITAP) conducted an economic evaluation of HLA-B*15:02 and suggested that universal $H L A-B * 15: 02$ screening was cost-effective in preventing Stevens-Johnson syndrome (SJS) and toxic epidermal necrolysis (TEN) in neuropathic pain patients treated with carbamazepine but was not cost-effective for epileptic patients [16]. The result, however, depended on the accuracy of the prevalence input in the economic model. The Department of Medical Sciences, in the same year, launched a project to provide $H L A-B^{*} 15: 02$ screening tests in the Bangkok area. The pilot project aimed to lessen carbamazepine-induced severe cutaneous adverse reactions (SCARs). In 2016, the project was expanded to other provinces and covered two additional genetic tests; $H L A-B * 57: 01$ and $H L A-B * 58: 01$ [17]. Thailand has 24 medical geneticists but does not have genetic counselors [5, 8]. The Pharmacogenetic ID card was developed and provided to patients who had undergone genetic tests to ensure patient safety [18]. Furthermore, a basic pharmacogenetics course is taught in both medical school and pharmacy school, but only for a few hours [19-23]. Genotyping laboratory services were available, but only in some government laboratory and super-tertiary hospitals, for example, in 15 centers of the Department of Medical Sciences and six university hospitals [24].

The Thai healthcare system is recognized internationally. All Thai citizens are covered under one of the three mandatory public health insurance schemes: (1) Civil Servant Medical Benefit Scheme (CSMBS) for government staff and their dependents, (2) Social Security Scheme (SSS) for private-sector workers and (3) Universal Coverage Scheme (UCS) for those not eligible for the CSMBS or SSS schemes. The CSMBS, SSS and UCS covered $7.73 \%, 18.84 \%$ and $70.75 \%$ of the Thai citizens, respectively [25]. All schemes provide a comprehensive package, including outpatient visits, hospital admission, accidental and emergency services, pharmaceutical benefits, x-ray and laboratory testing. 
All three schemes use a similar payment mechanism for in-patient services. UCS and CSMBS use diagnostic related groups (DRGs) with global budget payment, while SSS uses a combination of capitation and DRG with global budget payment. Drug, x-ray and laboratory testing are bundled with doctor visits under capitation payment. The CSMBS, on the other hand, uses per-item payment for pharmaceutical benefits and has a fee schedule for x-ray and laboratory testing [26, 27].

Although Thailand has a good performance of their health insurance system, inequity among the three public health insurers was observed. Patikorn et al. found that access to high-cost anti-cancer drugs was better among CSMBS than among SSS and UCS [26]. Sermsri et al. also confirmed the disparity of treatment choice among colorectal cancer patients in the CSMBS vs UCS schemes, thus resulting in a gap in treatment outcome [27].

The majority of the existing research in Thailand focuses on gene-disease association and the development of genetic testing methods. Very little attention has been paid to explore access to PM tests. This study intended to explore Thailand's health insurance coverage of PMs, especially genetic testing, among the three public health insurance schemes in Thailand. Potential factors associated with PM reimbursement were also explored.

\section{Methods}

This study utilized a targeted review method to evaluate patient access to PMs and explore factors that might be associated with PM testing reimbursement among three health insurance schemes in Thailand. Thirteen biomarkers were selected as a representative of four PM categories: (1) PM for targeted cancer drug selection, (2) PM for the prediction of druginduced SCARs, (3) PM for dose adjustment and (4) PM for cancer risk prediction. The basic characteristics of the $13 \mathrm{PMs}$ are described in Table 1 . The price range of the selected PM testing was very high in the BRCA1/2 gene (19,400-50,000 Thai baht), compared to 1,10011,000 Thai baht for other PM categories.

The framework of this study was adapted from Meckley and Neumann [7], which was composed of four variables: PM test reimbursement status, genetic test mentioning in clinical practice guidelines, genetic test information in drug labeling and value for money of the genetic test. Reimbursement status was determined as "Yes" only when reimbursement evidence was clearly stated in the official documents. Genetic test information in drug labeling was classified into three categories: "required," "recommended," and "informative." "Required" was assigned when genetic testing was stated or indicated necessary in drug labeling. "Recommended" was specified when drug labeling stated that genetic testing should be provided or performed. "Informative" was used when drug labeling provided information to educate readers. This study explored guidelines endorsed or created by the Royal College of Thai Physicians, and the results of the economic evaluation of PMs in the context of Thailand.

A comprehensive search was conducted in PubMed to identify relevant economic evaluation articles related to the 13 selected PMs in Thailand. Search terms included "(Name of genetic biomarkers) AND Thailand." Furthermore, the official websites of government organizations, insurers, national HTA organizations, and healthcare professionals were searched to ensure the completeness of information. The targeted search was conducted up until February 29, 2020. The language was limited to Thai and English. Content analysis was performed to compare access to PMs among CSMBS, SSS, and UCS in four aspects: reimbursement status, clinical practice guideline, statement in an FDA approved leaflet and economic evaluation results.

Ethical issue: Review paper do not need approval code 


\begin{tabular}{|c|c|c|c|c|c|}
\hline Biomarker & $\begin{array}{l}\text { Companion } \\
\text { drug/Therapy }\end{array}$ & $\begin{array}{l}\text { NLEM } \\
\text { status of } \\
\text { drug [28] }\end{array}$ & Benefits of PM tests & $\begin{array}{l}\text { Therapeutic } \\
\text { area }\end{array}$ & $\begin{array}{l}\text { Price of PM tests" } \\
\text { (2020 Thai baht) }\end{array}$ \\
\hline \multicolumn{6}{|c|}{ PM for targeted cancer drug selection } \\
\hline HER2/neu & Trastuzumab & NLEM & $\begin{array}{l}\text { Trastuzumab } \\
\text { candidate }\end{array}$ & Oncology & 10,000 \\
\hline \multirow[t]{3}{*}{$B C R-A B L$} & Imatinib & NLEM & $\begin{array}{l}\text { Tyrosine kinase } \\
\text { inhibitors candidate }\end{array}$ & Oncology & $1,100-6,000$ \\
\hline & Nilotinib & NLEM & & Oncology & \\
\hline & Dasatinib & NLEM & & Oncology & \\
\hline \multirow[t]{2}{*}{$\begin{array}{l}\text { EGFR } \\
\text { mutation }\end{array}$} & Gefitinib" & $\begin{array}{l}\text { Non- } \\
\text { NLEM }\end{array}$ & $\begin{array}{l}\text { EGFR inhibitors } \\
\text { candidate }\end{array}$ & Oncology & $7,000-11,000$ \\
\hline & Erlotinib & $\begin{array}{l}\text { Non- } \\
\text { NLEM }\end{array}$ & & Oncology & \\
\hline \multicolumn{6}{|c|}{ PM for the prediction of drug-induced SCARS } \\
\hline $\begin{array}{l}H L A- \\
B^{*} 15: 02\end{array}$ & Carbamazepine & NLEM & $\begin{array}{l}\text { Prevent drug- } \\
\text { induced SJS/TEN }\end{array}$ & Neurology & $1,000-2,000$ \\
\hline $\begin{array}{l}H L A- \\
B^{*} 57: 01\end{array}$ & Abacavir & NLEM & $\begin{array}{l}\text { Prevent drug- } \\
\text { induced HSR }\end{array}$ & $\begin{array}{l}\text { Infectious } \\
\text { diseases }\end{array}$ & $1,000-2,000$ \\
\hline $\begin{array}{l}H L A- \\
B^{*} 58: 01\end{array}$ & Allopurinol & NLEM & $\begin{array}{l}\text { Prevent drug- } \\
\text { induced SJS/TEN }\end{array}$ & Rheumatology & $1,000-2,000$ \\
\hline \multicolumn{6}{|c|}{ PM for dose adjustment } \\
\hline$T P M T$ & Azathioprine & NLEM & $\begin{array}{l}\text { Predict azathioprine- } \\
\text { related bone marrow } \\
\text { toxicity }\end{array}$ & Rheumatology & $1,800-3,400$ \\
\hline$U G T 1 A 1$ & Irinotecan & $\begin{array}{l}\text { Non- } \\
\text { NLEM }\end{array}$ & $\begin{array}{l}\text { Predict irinotecan- } \\
\text { related toxicity }\end{array}$ & Oncology & $1,400-1,700$ \\
\hline СУР2C19 & Clopidogrel & NLEM & $\begin{array}{l}\text { Monitoring response } \\
\text { to clopidogrel } \\
\text { therapy }\end{array}$ & Cardiology & $1,800-3,500$ \\
\hline СYР2C9 & Warfarin & NLEM & $\begin{array}{l}\text { Adjust warfarin } \\
\text { dosing }\end{array}$ & Hematology & $1,000-2,000$ \\
\hline VKORC1 & Warfarin & NLEM & $\begin{array}{l}\text { Adjust warfarin } \\
\text { dosing }\end{array}$ & Hematology & 2,950 \\
\hline CYP2D6 & Tamoxifen & NLEM & $\begin{array}{l}\text { Monitor tamoxifen } \\
\text { efficacy }\end{array}$ & Oncology & $1,800-4,800$ \\
\hline \multicolumn{6}{|c|}{$P M$ for cancer risk prediction } \\
\hline BRCA1/2 & \multicolumn{2}{|c|}{$\begin{array}{l}\text { Breast cancer monitoring/ } \\
\text { mastectomy }\end{array}$} & $\begin{array}{l}\text { Assess risk of breast } \\
\text { or ovarian cancer } \\
\text { development }\end{array}$ & Oncology & $19,400-50,000$ \\
\hline
\end{tabular}

Table 1.

Characteristics of 13 studied precision medicines
Note(s): $"=$ Drug not listed in the National List of Essential Medicine (NLEM) but reimbursed under the CSMBS Oncology Prior Authorisation (OCPA) list

$*$ = Published price list from Chulalongkorn Memorial Hospital, Ramathibodi Hospital and Siriraj Hospital [29-31]

Abbreviations: HSR; hypersensitivity reactions, NLEM; national list of essential medicines of Thailand, PM; precision medicine, SCARs; severe cutaneous adverse reactions, SJS/TEN; Stevens-Johnson syndrome/toxic epidermal necrolysis

\section{Results}

Reimbursement status of the selected precision medicines

The reimbursement status of the selected PMs across the three public health insurance schemes in Thailand is summarized in Table 2. Overall, CSMBS patients have access to 10 out 


\begin{tabular}{|c|c|c|c|c|c|c|c|c|}
\hline \multirow{2}{*}{$\begin{array}{l}\text { Precision } \\
\text { medicine } \\
\text { test } \\
\text { Biomarker }\end{array}$} & \multicolumn{3}{|c|}{$\begin{array}{c}\text { Reimbursement } \\
\text { status }\end{array}$} & \multicolumn{2}{|c|}{ Clinical practice guideline } & \multirow{2}{*}{$\begin{array}{l}\text { Statement in } \\
\text { FDA approved } \\
\text { leaflet }\end{array}$} & \multirow{2}{*}{$\begin{array}{l}\text { Economic } \\
\text { evaluation } \\
\text { results }\end{array}$} & \multirow{2}{*}{$\begin{array}{r}\text { Access to } \\
\text { precision } \\
\text { medicine in } \\
\text { Thailand }\end{array}$} \\
\hline & CSMBS & SSS & UCS & International & Thai & & & \\
\hline \multicolumn{9}{|c|}{$P M$ for targeted cancer drug selection } \\
\hline HER2/neu & $\begin{array}{l}\text { Yes } \\
{[32]}\end{array}$ & $\begin{array}{l}\text { Yes } \\
{[33]}\end{array}$ & $\begin{array}{l}\text { Yes } \\
{[34]}\end{array}$ & $\begin{array}{l}\text { NCCN2020 [35], } \\
\text { ESMO2019 [36] }\end{array}$ & $\begin{array}{l}\text { NCI } 2017 \\
{[37]}\end{array}$ & Required & $\begin{array}{l}\text { Cost-effective } \\
{[38]^{*}}\end{array}$ & 279 \\
\hline$B C R-A B L$ & $\begin{array}{l}\text { Yes } \\
{[32]}\end{array}$ & $\begin{array}{l}\text { Yes } \\
{[33]}\end{array}$ & $\begin{array}{l}\text { Yes } \\
{[34]}\end{array}$ & $\begin{array}{l}\text { NCCN2020 [39], } \\
\text { ESMO2017 [40] }\end{array}$ & $\begin{array}{l}\text { ThaiCML } \\
2011 \text { [41] }\end{array}$ & Required & $\begin{array}{l}\text { Cost-effective } \\
{[42]^{*}}\end{array}$ & \\
\hline $\begin{array}{l}\text { EGFR } \\
\text { mutation }\end{array}$ & $\begin{array}{l}\text { Yes } \\
{[32]}\end{array}$ & No & No & $\begin{array}{l}\text { NCCN2020 [43], } \\
\text { ESMO2018 [44] }\end{array}$ & $\begin{array}{l}\mathrm{NCI} 2015 \\
{[45]}\end{array}$ & Required & $\begin{array}{l}\text { Cost-effective } \\
{[46]}\end{array}$ & \\
\hline \multicolumn{9}{|c|}{ PM for the prediction of drug-induced SCARS } \\
\hline $\begin{array}{l}H L A- \\
B^{*} 15: 02\end{array}$ & $\begin{array}{l}\text { Yes } \\
{[47]}\end{array}$ & No & $\begin{array}{l}\text { Yes } \\
{[48]}\end{array}$ & $\begin{array}{l}\text { CPIC2018 [49], } \\
\text { CPNDS2014 [50] }\end{array}$ & $\begin{array}{l}\text { Thai } \\
\text { epilepsy } \\
\text { society } 2011 \\
{[51]}\end{array}$ & Required & $\begin{array}{l}\text { - Neuropathic } \\
\text { pain: cost- } \\
\text { effective } \\
\text { - Epilepsy: Not } \\
\text { cost-effective } \\
\text { [16] }\end{array}$ & \\
\hline $\begin{array}{l}H L A- \\
B^{*} 57: 01\end{array}$ & $\begin{array}{l}\text { Yes } \\
{[52]}\end{array}$ & No & No & $\begin{array}{l}\text { WHO2016 [53], } \\
\text { CPIC2012 [54], } \\
\text { DPWG2019 [55] }\end{array}$ & $\begin{array}{l}\text { Thai AIDS } \\
\text { society } 2017 \\
{[56]}\end{array}$ & Recommended & $\begin{array}{l}\text { Study not } \\
\text { found }\end{array}$ & \\
\hline $\begin{array}{l}H L A- \\
B^{*} 58: 01\end{array}$ & $\begin{array}{l}\text { Yes } \\
{[47]}\end{array}$ & No & No & $\begin{array}{l}\text { ACR2012 [57], } \\
\text { CPIC2013 [58] }\end{array}$ & & Recommended & $\begin{array}{l}\text { Cost-effective } \\
\text { [59] }\end{array}$ & \\
\hline \multicolumn{9}{|c|}{ PM for dose adjustment } \\
\hline$T P M T$ & $\begin{array}{l}\text { Yes } \\
{[47]}\end{array}$ & No & No & $\begin{array}{l}\text { CPIC2018 [60], } \\
\text { DPWG2019 [61] }\end{array}$ & & Informative & $\begin{array}{l}\text { Study not } \\
\text { found }\end{array}$ & \\
\hline$U G T 1 A 1$ & No & No & No & $\begin{array}{l}\text { NCCN2020[ [62]), } \\
\text { DPWG2018 [63] }\end{array}$ & & Informative & $\begin{array}{l}\text { Study not } \\
\text { found }\end{array}$ & \\
\hline СУР2С19 & $\begin{array}{l}\text { Yes } \\
{[47]}\end{array}$ & No & No & $\begin{array}{l}\text { ACCF/AHA/SCAI2011 } \\
\text { [64], ACCF/AHA/ACP/ } \\
\text { AATS/ PCNA/SCAI/ } \\
\text { STS2012 [65], CPIC2013 } \\
\text { [66], DPWG2018 [67] }\end{array}$ & $\begin{array}{l}\text { Thai heart } \\
2014 \text { [68] }\end{array}$ & Informative & $\begin{array}{l}\text { Study not } \\
\text { found }\end{array}$ & \\
\hline СYР2C9 & $\begin{array}{l}\text { Yes } \\
{[47]}\end{array}$ & No & No & $\begin{array}{l}\text { CPIC2017 [69], } \\
\text { DPWG2018 [70], } \\
\text { CPNDS2015 [71] }\end{array}$ & $\begin{array}{l}\text { Thai heart } \\
2014 \text { [68] }\end{array}$ & Informative & $\begin{array}{l}\text { Non cost- } \\
\text { effectiveness } \\
{[72]}\end{array}$ & \\
\hline VKORC1 & No & No & No & $\begin{array}{l}\text { CPIC2017 [69], } \\
\text { DPWG2018 [73], } \\
\text { CPNDS2015 [71] }\end{array}$ & & Informative & $\begin{array}{l}\text { Non cost- } \\
\text { effectiveness } \\
{[72]}\end{array}$ & \\
\hline CYP2D6 & No & No & No & $\begin{array}{l}\text { CPIC2018 [74], } \\
\text { DPWG2018 [75], } \\
\text { CPNDS2019 [76] }\end{array}$ & & Informative & $\begin{array}{l}\text { Study not } \\
\text { found }\end{array}$ & \\
\hline \multicolumn{9}{|c|}{$P M$ for cancer risk prediction } \\
\hline$B R C A 1 / 2$ & $\begin{array}{l}\text { Yes } \\
{[47]}\end{array}$ & No & No & $\begin{array}{l}\text { NCCN2018 [77], } \\
\text { ESMO2016 [78] }\end{array}$ & & - & $\begin{array}{l}\text { Study not } \\
\text { found }\end{array}$ & \\
\hline
\end{tabular}

Note(s): * = companion drug and PM test were bundled when conducting economic analysis

Abbreviations: ACCF: American College of Cardiology Foundation, ACR: American College of Radiology, AHA: American Heart Association, CML: chronic myeloid leukemia, CPIC: Clinical Pharmacogenetics Implementation Consortium, CPNDS: Canadian Pharmacogenomics Network for Drug Safety, CSMBS: Civil Servant Medical Benefit Scheme, DPWG: Dutch Pharmacogenetics Working Group, ESMO: European Society for Medical Oncology, FDA: Food and Drug Administration, NCCN: National Comprehensive Cancer Network, NCI: National Cancer Institute, SCAI: Society for Cardiovascular Angiography and Interventions, SCARs: Severe cutaneous adverse reactions, SSS: Social Security Scheme, UCS: Universal Coverage Scheme, WHO: World Health Organization

Table 2.

Reimbursement status, clinical practice guideline, economic evaluation findings and information in the leaflets of $13 \mathrm{PMs}$ 
JHR

36,2

280 of 13 tests $(77 \%)$, followed by 3 tests for UCS patients $(23 \%)$ and 2 tests for SSS patients $(15 \%)$. The companion drugs of the selected PMs were mostly listed in the National List of Essential Medicines (NLEM) of Thailand except for gefitinib, erlotinib and irinotecan. The NLEM drugs were reimbursable for patients in all insurance schemes. However, CSMBS patients can still access non-NLEM drugs previously mentioned through different channels such as the OCPA program or prescribing criteria for non-NLEM drugs.

Among four PM types, PM for targeted cancer drug selection was more likely to be reimbursed by all schemes. All three tests $(100 \%)$ were reimbursed by CSMBS, while two tests $(67 \%)$ were reimbursed by UCS and SSS. The reimbursement status of three pharmacogenetic tests for the prediction of drug-induced SCARs was positive among all three tests $(100 \%)$ for CSMBS, followed by one test $(33 \%)$ and none $(0 \%)$ for UCS and SSS. Three out of six $(50 \%)$ pharmacogenetic tests for dose adjustment purpose were reimbursed only by CSMBS, while none of them was reimbursed by UCS and SSS. The cancer risk prediction, namely the $B R C A 1 / 2$ gene, was reimbursable only for CSMBS patients. It is worth noting that the purpose of PMs may somehow be associated with the reimbursement decision.

\section{Factors associated with precision medicine reimbursement}

The possible association was observed across PM types and insurance schemes. The results were described in the following three topics.

Clinical practice guideline. All selected PMs across the four categories were recommended in the international guidelines. However, only five PMs were recommended in the Thai guidelines including three PMs for targeted cancer drug selection (HER2/neu, BCR-ABL and EGFR mutation) [37, 41, 45], and two PMs for the prediction of drug-induced SCARs (HLA$B^{*} 15: 02$ and $\left.H L A-B^{*} 57: 01\right)[51,56]$. Furthermore, the Thai guideline mentioned about two biomarkers for dose adjustment for warfarin therapy (CYP2C9 and VKORC1) [68]. There was no local guideline for the other six PMs. Out of six Thai clinical practice guidelinerecommended PMs, the reimbursable status was positive in five tests for CSMBS (100\%), followed by three tests for UCS $(60 \%)$ and two tests for SSS (40\%).

Statement in the FDA-approved leaflet. The statements in the FDA-approved leaflet were found to be "Required" in three PMs, "Recommended" in two PMs and "Informative" for seven PMs. The two reimbursable tests were "Required" for SSS. Out of three reimbursable tests for UCS, two tests were "Required," and one test was "Recommended." None of the "Informative" PMs were reimbursable for UCS and SSS. For CSMBS, all of the PMs with a statement in the FDA approved leaflet as either "Required" or "Recommended" were reimbursable. However, four out of seven "Informative" PMs were reimbursable. In contrast, the BRCA1/2 gene had no stated information in any FDA-approved leaflet's medicine because both biomarkers were not directly paired with any medicine.

Economic evaluation. Economic evaluation studies were conducted in Thailand assessing six PMs including HER2/neu [38], BCR-ABL [42], EGFR mutation [46], HLA-B*15:02 [16], $H L A-B^{*} 58: 01$ [59] and CYP2C9 [72]. All of these studies showed that the use of PMs was cost-effective with the exception of the test for $H L A-B^{*} 15: 02$ in epilepsy patients planning to start carbamazepine to prevent drug-induced SJS/TEN [16], and test for CYP2C9 to adjust warfarin dosing [72]. Among five cost-effective PMs, the reimbursement status was positive in five tests for CSMBS $(100 \%)$, followed by three tests for UCS $(60 \%)$ and two tests for SSS $(40 \%)$. On the other hand, out of two cost-ineffective PMs, the reimbursement status was positive for two tests for CSMBS patients, followed by one test for UCS and none for SSS.

\section{Discussion}

This was the first study to explore the situation of access to PMs in Thailand. The selected PM tests covered 13 out of 50s biomarkers from 4 PM categories. Compared to previous 
studies that evaluated access to PMs in the USA, the UK [7] and four Southeast Asian countries [8], this study covered more PM items.

It is still unclear how PM testing was listed in three health insurance benefits packages. However, the reimbursement seemed to favor PMs with drug selection and serious ADR prevention purposes. Among drug selection purposes, PM test reimbursement status was highly associated with its companion drug reimbursement status. Economic evaluation results seemed to impact drug selection, thus indirectly influencing access to companion PM testing for drug selection purposes. It is quite clear in this case that economic evaluation might be a major factor driving the reimbursement decision of both genetics testing and its companion drug in Thailand. However, the factor influencing the reimbursement decision in Thailand was different from the factors found in the United States and the United Kingdom. The strength of clinical evidence and the availability of clinical guidelines strongly predicted the reimbursement decisions of PMs, while the regulatory status and economic evaluations were not [7].

The reimbursement decision of PM testing for the prediction of drug-induced SCARs was unclear. In 2009, several studies reported higher carbamazepine-induced SJS/TEN incidents among more Asians than Caucasians. Later, Tassaneeyakul et al. confirmed that Thais had a very high risk of carbamazepine-induced SJS/TEN. The study recommended that the HLA$B * 15: 02$ should be screened before starting carbamazepine [79]. The government expressed their concern related to pharmacogenetic by launching the first pilot project for HLA$B * 15: 02$ testing among patients initiating carbamazepine in 2013. Later, the project was expanded to cover more hospitals and two more pharmacogenetic tests: $H L A-B * 57: 01$ for abacavir and $H L A-B * 58: 01$ for allopurinol. It took about five years to list $H L A-B^{*} 15: 02$ for epilepsy patients initiating carbamazepine in the UCS benefit package. Six months later, UCS expanded the coverage of $H L A-B * 15: 02$ for carbamazepine among patients suffering from neuropathic pain $[48,80]$. The reimbursement decision was contradicted with the economic evaluation result as $H L A-B^{*} 15: 02$ was not cost-effective for epilepsy but cost-effective for the neuropathic pain subgroup [16].

Although $H L A-B^{*} 58: 01$ was included in a pilot project since 2016 and the costeffectiveness result was confirmed [59], the decision to include $H L A-B^{*} 58: 01$ was not reached. At least two actions - (1) adding information about the association between HLA$B^{*} 58: 01$ and SCARs in the product leaflet and (2) inclusion of febuxostat as a restricted benefit in the NLEM list D - were taken to prevent severe ADR in a mean time [28]. Febuxostat was restrictively prescribed only when patients were $H L A-B * 58: 01$ positive.

Furthermore, an increasing trend of Abacavir use was observed. Abacavir was listed $D$ in NLEM as a combination drug to treat HIV patients since 2019 [81, 82]. Abacavir was the only drug in the nucleoside reverse transcriptase inhibitor (NRTI) category not requiring dose adjustment in patients with renal impairment [56]. HLA-B*57:01 testing before prescribing Abacavir was recommended by several practice guidelines, both internationally and domestically. Moreover, the Thai FDA also recommended in the leaflet that patients should take an $H L A-B * 57: 01$ test before using Abacavir. Although $H L A-B^{*} 57: 01$ was included in a phase II pharmacogenomic pilot project since 2016, at the time of conducting this research, SSS and UCS had not yet included it in their benefits packages. One possible explanation was the incidence of serious ADR was low among Asian people [56]. This evidence corresponded to previous studies that showed that the prevalence of $H L A-B * 57: 01$ was found at a lower rate among Chinese, Thai and Cambodian people compared to Europeans [83, 84].

It was unlikely that insurers supported biomarkers with dose adjustment purposes. In general, patients taking drugs such as warfarin should have regular clinical monitoring. CYP2C9 and VKORC1 were mentioned in the clinical guideline as they are pharmacogenetic makers that are highly associated with warfarin metabolism. This information, however, was not translated into a strong recommendation in the FDA-approved leaflet. One possible explanation was that regardless of the existing genes, the doctors should still closely monitor 
JHR

36,2
INR and ADR among patients receiving warfarin [68]. The economic evaluation also confirmed that CYP2C9 and VKORC1 were not cost-effective [72].

$B R C A 1 / 2$ was reimbursed only under CSMBS. Treatment options like mastectomy and salpingo-oophorectomy need not only patients' understanding and involvement [85, 86], but also financial coverage from health insurers when patients decide to undergo those surgeries to prevent breast and ovarian cancer [87].

The costs of PM testing for targeted cancer drug selection were not solely covered by the three health insurance schemes, especially for non-NLEM drugs. Patikorn $e$ al also found that the costs of PM testing for targeted cancer drug selection were also covered by pharmaceutical companies under Patient Assistance Programs (PAPs) such as the HER2/mue gene for trastuzumab and EGFR mutation for gefitinib [26]. This strategy was probably done with the intention to mitigate the costs of PM tests from both the healthcare providers and patients.

As this study utilized the document review method, the result reflected only the official PM coverage policy obtained from official documents which was considered a major limitation of the study. First, access to PMs in real practice might be deviated from official announcements due to the differences in healthcare financing mechanisms of the three health insurance schemes, especially for SSS and UCS. Doctors could order PM tests to ensure patient safety. Although PMs were not listed in the benefits package, their expenditure would be absorbed by the hospitals under the capitation payment scheme. Unlike CSMBS, PMs were reimbursed only if they were in the benefits package and paid for under the per item payment system. If doctor-prescribed PMs are not listed in the benefits package, CSMBS patients are required to pay out of their own pocket. It could be implied that under some circumstances, healthcare professionals might be reluctant to provide PM tests for patients in need, especially those under UCS and SSS, because there is no clear list of reimbursable tests. Second, the factors found to likely influence the reimbursement decisions in this study were based on a retrospective review of literature and government documents. Under some circumstances, the reimbursement decisions might not be made based on either the statement in FDA approved leaflets or the economic evaluation results.

With the previously mentioned limitation, additional in-depth interviews with healthcare professionals, payers and policymakers are recommended for future research to explore practice variation, perspective on PMs and reimbursement decisions framework. PMs are well known among healthcare professions in Thailand; however, very little was known about the general people's perception. The payers or responsible organizations in Thailand should consider formulating not only HTA guidelines specific to PM tests but also develop a reimbursement list of PM tests. PM tests that are proven to be valuable for the health system should be unbundled from the capitation payment scheme to increase access to PM tests for the Thai population. Patients should also be empowered and be able to communicate risks associated with their existing genetics to their doctors to ensure safe drug administration. Patient education about PM is needed.

\section{Conclusion}

The study showed that there was a discrepancy in access to PMs among the three public health insurance schemes in Thailand. CSMBS is the most generous scheme compared to SSS and UCS in providing their beneficiaries the access to PMs. Three health insurance schemes provided adequate access to PM tests for some cancer-targeted therapies, while gaps existed for access to PM tests for serious ADRs prevention, dose adjustment and cancer risk prediction. Clinical practice guidelines may not be considered factors associated with PM reimbursement status as the major aim is to provide educational information. Although local clinical guidelines were not available for all drug biomarkers, healthcare professionals normally refer to the international guidelines. Statements in the FDA-approved leaflet, which are indicated as "required" and "recommended," seemed to have an impact on the 
reimbursement status of CSMBS, while "required" likely impacted the reimbursement status of SSS and UCS. Economic evaluation seems to influence PM reimbursement decisions of SSS and UCS, while CSMBS reimbursed PMs regardless of economic evaluation results. However, there was no specific HTA guideline. It is therefore suggested that PM-specific HTA guidelines should be established.

Conflict of Interest: None

\section{References}

1. National Human Genome Research Institute $[\mathrm{NIH}$ ]. The human genome project. [updated 2019 October 7; cited 2020 March 13]. Available from: https://www.genome.gov/human-genome-project.

2. Personalized Medicine Coalition [PMC]. Personalized medicine at FDA: a progress and outlook report. [cited 2020 March 13]. Available from: http://www.personalizedmedicinecoalition.org/ Userfiles/PMC-Corporate/file/PM_at_FDA_A_Progress_and_Outlook_Report.pdf.

3. US Food and Drug Administration [FDA]. Table of pharmacogenomic biomarkers in drug labeling. [updated 2019 December; cited 2020 March 10]. Available from: https:/www.fda.gov/ Drugs/ScienceResearch/ucm572698.htm.

4. Clinical Pharmacogenetics Implementation Consortium [CPIC]. Genes-drugs. [updated 2019 November 7; cited 2020 March 15]. Available from: https://cpicpgx.org/genes-drugs/.

5. Shotelersuk V, Tongsima S, Pithukpakorn M, Eu-Ahsunthornwattana J, Mahasirimongkol S. Precision medicine in Thailand. Am J Med Genet C Semin Med Genet. 2019; 181(2): 245-253. doi: 10.1002/ajmg.c.31694.

6. Pothier KC. Personalizing precision medicine : a global voyage from vision to reality. Hoboken, NJ: Wiley; 2017.

7. Meckley LM, Neumann PJ. Personalized medicine: factors influencing reimbursement. Health Pol. 2010; 94(2): 91-100. doi: 10.1016/j.healthpol.2009.09.006.

8. Chong HY, Allotey PA, Chaiyakunapruk N. Current landscape of personalized medicine adoption and implementation in Southeast Asia. BMC Med Genomics. 2018; 11(1): 94. doi: 10.1186/s12920018-0420-4.

9. Charoensiriwatana W, Janejai N, Boonwanich W, Krasao P, Chaisomchit S, Waiyasilp S. Neonatal screening program in Thailand. Southeast Asian J Trop Med Public Health. 2003; 34(Suppl 3): $94-100$.

10. Chaibunruang A, Sornkayasit K, Chewasateanchai M, Sanugul P, Fucharoen G, Fucharoen S. Prevalence of thalassemia among newborns: a re-visited after 20 years of a prevention and control program in Northeast Thailand. Mediterr J Hematol Infect Dis. 2018; 10: e2018054. doi: 10.4084/ MJHID.2018.054.

11. Shotelersuk V, Limwongse C, Mahasirimongkol S. Genetics and genomics in Thailand: challenges and opportunities. Mol Genet Genomic Med. 2014; 2(3): 210-216. doi: 10.1002/mgg3.83.

12. National Center for Genet. ic Engineering and Bi. otechnology [BIOTEC]. Annual report 2017. Pathum Thani: BIOTEC; 2018.

13. Thailand, Ministry of Public Health. Office of the permanent secretary, strategy and planning division. Twenty-year national strategic plan for public health (2017-2036). Nonthaburi: Strategy and Planning Division, Office of the Permanent Secretary; 2018.

14. Shotelersuk V. Precision medicine for rare diseases. International conference on precision medicine from discovery to public health. Bangkok; 2018. [cited 2020 March 15]. Available from: http://media.md.chula.ac.th/PrecisionMedicine/handbook\%20final.pdf.

15. Pithukpakorn M. Precision medicine: current situation in Thailand. Precision medicinein Thailand 4.0. Bangkok; 2019. [cited 2020 March 12]. Available from: https://op.mahidol.ac.th/ra/contents/ orra_document/CONFERENCE/20190806-08_SUMMARY.pdf. 
JHR

36,2
16. Rattanavipapong W, Koopitakkajorn T, Praditsitthikorn N, Mahasirimongkol S, Teerawattananon Y. Economic evaluation of HLA-B*15:02 screening for carbamazepine-induced severe adverse drug reactions in Thailand. Epilepsia. 2013; 54(9): 1628-1638. doi: 10.1111/epi.12325.

17. Thailand, Ministry of Public Health, Department of Medical Sciences. Relaese information of Department of Medical Sciences supported two public hospitals to provide PGx testing services for reducing drug-induced SCARs. [updated 2016 July 15; cited 2020 March 15]. Available from: http://www.dmsc.moph.go.th/dmscnew_old/news_detail.php?cid=1\&id=1426.

18. Sukasem C, Chantratita W. A success story in pharmacogenomics: genetic ID card for SJS/TEN. Pharmacogenomics. 2016; 17(5): 455-458. doi: 10.2217/pgs-2015-0009.

19. Mahidol University, Faculty of pharmacy. Doctor of pharmacy program. [cited 2020 March 15]. Available from: https://www.pharmacy.mahidol.ac.th/eng/degreeadmission_bac.php.

20. Chulalongkorn University. Faculty of pharmaceutical sciences. Doctor of pharmacy program in pharmaceutical care. [cited 2020 March 15]. Available from: https://www.pharm.chula.ac.th/

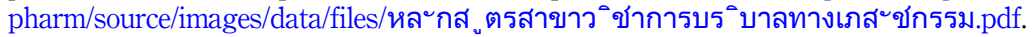

21. Chulalongkorn University, Faculty of pharmaceutical sciences. Doctor of pharmacy program in industrial pharmacy. [cited 2020 March 15]. Available from: https://www.pharm.chula.ac.th/

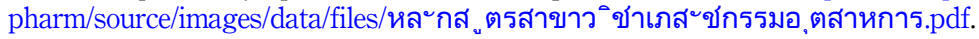

22. Chulalongkorn University, Faculty of medicine. Doctor of Medicine. Bangkok: Faculty of Medicine, Chulalongkorn University; 2014. [cited 2020 March 15]. Available from: http:/acad.md. chula.ac.th/upload/category/32/0_1517476536.pdf.

23. Mahidol University. Faculty of medicine Ramathibodi hospital. Doctor of Medicine. Bangkok: Faculty of Medicine Ramathibodi Hospital, Mahidol University; 2020. [cited 2020 March 15]. Available from: https://www.rama.mahidol.ac.th/meded/sites/default/files/public/img2019/pdf/ report $\% 20 \mathrm{TQF} \% 20 \mathrm{MD}-63 \% 20251062$.pdf.

24. Thailand, Ministry of Public Health, Department of Medical Sciences. Department of Medical Sciences, Ministry of Public Health. Nonthaburi: Department of Medical Sciences; 2017.

25. National Health Security Office [NHSO]. UC information. [updated 2020 March; cited 2020 March 15]. Available from: https://ucinfo.nhso.go.th/ucinfo.

26. Patikorn C, Taychakhoonavudh S, Thathong T, Anantachoti P. Patient access to anti-cancer medicines under public health insurance schemes in Thailand: a mixed methods study. Thai Journal of Pharmaceutical Sciences. 2019; 43(3): 168-178.

27. Sermsri N, Boonpipattanapong T, Prechawittayakul P, Sangkhathat S. Influence of payer source on treatment and outcomes in colorectal cancer patients in a university hospital in Thailand. Asian Pac J Cancer Prev. 2014; 15(20): 9015-9019. doi: 10.7314/apjcp.2014.15.20.9015.

28. Sarikulya C. Notification of the national drug system development committee national list of essential medicines B.E. 2562 (A.D. 2019). Thai Government Gazette No. 136; 2019.

29. Mahidol University, Faculty of Medicine Siriraj Hospital. Office for research and development. Molecular genetic testing (DNA analysis). [cited 2020 March 12]. Available from: https://www.si. mahidol.ac.th/th/manual/a10.htm.

30. Mahidol University. Faculty of medicine Ramathibodi hospital, department of pathology. PPM Ramathibodi Hospital. Pharmacogenomics test request form. [cited 2020 March 12]. Available from: http://med.mahidol.ac.th/patho/th/Laboratory/Pharmacogenomics.

31. Faculty of Medicine Chulalongkorn University/King Chulalongkorn Memorial Hospital. Center for Medical Diagnostic Laboratories. Laboratory request form. [cited 2020 March 15]. Available from: https://cmdl.md.chula.ac.th/form/LaboratoryRequestForm-public.pdf.

32. Sakolsatayadorn P. Notification of the ministry of public health medical health service fees of service units under the ministry of public health B.E. 2562 (A.D. 2019). Thai Government Gazette No. 136; 2019.

33. Banchuen C. Announcement of the medical committee under the social security Act B.E. 2562 (A.D. 2019). Thai Government Gazette No. 137; 2020. 
34. National Health Security Office [NHSO]. National health security Fund management manual: Fiscal year 2020. Bangkok: NHSO; 2019.

35. National Comprehensive Cancer Network [NCCN]. NCCN clinical practice guidelines in oncology (NCCN Guidelines): breast cancer. Plymouth Meeting, PA: NCCN; 2020.

36. Cardoso F, Kyriakides S, Ohno S, Penault-Llorca F, Poortmans P, Rubio IT, et al. Early breast cancer: ESMO Clinical Practice Guidelines for diagnosis, treatment and follow-up. Ann Oncol. 2019; 30(8): 1194-1220. doi: 10.1093/annonc/mdz173.

37. Thailand, National Cancer Institutes [NCI]. Clinical practice guidelines for the diagnosis and treatment of Breast Cancer. Bangkok: Kositpress; 2017.

38. Kongsakon R, Lochid-amnuay S, Kapol N, Wiratkapun C. Economic evaluation of Trastuzumab for treatment of breast cancer in Thailand. Nonthaburi: National Drug Information; 2012.

39. National Comprehensive Cancer Network [NCCN]. NCCN clinical practice guidelines in oncology (NCCN Guidelines): Chronic lymphocytic leukemia. Plymouth Meeting, PA: NCCN; 2020.

40. Hochhaus A, Saussele S, Rosti G, Mahon FX, Janssen J, Hjorth-Hansen H, et al. Chronic myeloid leukaemia: ESMO Clinical Practice Guidelines for diagnosis, treatment and follow-up. Ann Oncol. 2017; 28(Suppl.4): iv41-51. doi: 10.1093/annonc/mdx219.

41. Thai Society of Hematology. Clinical practice guidelines for the treatment of chronic myeloid leukemia in Thailand. [updated 2011 May 9; cited 2020 March 13]. Available from: http://www.tsh. or.th/files_news/newsFile_20110509164226.pdf.

42. Kulpeng W, Sompitak S, Jootar S, Chansung K, Teerawattananon Y. Cost-utility analysis of dasatinib and nilotinib in patients with chronic myeloid leukemia refractory to first-line treatment with imatinib in Thailand. Clin Ther. 2014; 36(4): 534-543. doi: 10.1016/j.clinthera. 2014.02.008.

43. National Comprehensive Cancer Network [NCCN]. NCCN clinical practice guidelines in oncology (NCCN Guidelines): non-small cell lung cancer. Plymouth Meeting, PA: NCCN; 2020.

44. Postmus PE, Kerr KM, Oudkerk M, Senan S, Waller DA, Vansteenkiste J, et al. Early and locally advanced non-small-cell lung cancer (NSCLC): ESMO Clinical Practice Guidelines for diagnosis, treatment and follow-up. Ann Oncol. 2017; 28(Suppl.4): iv1-21. doi: 10.1093/annonc/ mdx222.

45. Thailand, National Cancer Institutes. Clinical practice guidelines for the diagnosis and treatment of lung cancer (2nd update). Bangkok: Kositpress; 2015. [cited 2020 March 15]. Available from: http://www.nci.go.th/th/cpg/Cervical_Cancer5.pdf.

46. Siritanadeepun T, Hanvoravongchai P, Sriuranpong V, Parinyanitikul N, Sitthideatphaiboon P, Poovorawan N, et al. The cost-effectiveness analysis of EGFR mutation test for management of advanced non-small cell lung cancer in Thailand. J Clin Oncol. 2016; 34(15_suppl): e20636. doi: 10. 1200/JCO.2016.34.15_supll.e20636.

47. Rattanachot S. Announcement of the Comptroller General's Department No. AC 0416.2/W393 Public health service fees, category No.6: blood service fees and categories No.7: diagnostic fees (October B.E. 2560) (2017 October 10). Available from: https://ww2.chi.or.th/dataupload/Ss/Ref/ 2561/W.393.pdf.

48. Sakolsatayadorn P. Announcement of national health security board types and limits of health service (No.17) B.E. 2562 (A.D. 2019). Thai Government Gazette No. 136; 2019.

49. Phillips EJ, Sukasem C, Whirl-Carrillo M, Muller DJ, Dunnenberger HM, Chantratita W, et al. Clinical pharmacogenetics implementation consortium guideline for HLA genotype and use of carbamazepine and oxcarbazepine: 2017 Update. Clin Pharmacol Ther. 2018; 103(4): 574-581. doi: 10.1002/cpt.1004.

50. Amstutz U, Shear NH, Rieder MJ, Hwang S, Fung V, Nakamura H, et al. Recommendations for HLA-B*15:02 and HLA-A*31:01 genetic testing to reduce the risk of carbamazepine-induced hypersensitivity reactions. Epilepsia. 2014; 55(4): 496-506. doi: 10.1111/epi.12564.

51. Epilepsy Society of Thailand. Clinical practice guidelines for epilepsy. Bangkok: Tanapress; 2018. 
JHR

36,2

286

52. Rattanachot S. Announcement of the Comptroller General's Department No. AC 0416.2/W372 Public health service fees, category No.6: blood service fees and categories No.7: diagnostic fees (August B.E. 2561); 2018. Available from: http://personal.sru.ac.th/2018/09/26/0416-2_372-22-08-2561/.

53. World Health Organization [WHO]. Consolidated guidelines on the use of antiretroviral drugs for treating and preventing HIV infection: recommendations for a public health approach. Geneva: WHO; 2016.

54. Martin MA, Klein TE, Dong BJ, Pirmohamed M, Haas DW, Kroetz DL, et al. Clinical pharmacogenetics implementation consortium guidelines for HLA-B genotype and abacavir dosing. Clin Pharmacol Ther. 2012; 91(4): 734-738. doi: 10.1038/clpt.2011.355.

55. The Royal Dutch Pharmacists Association. Annotation of DPWG guideline for abacavir and HLA-B 2019. [updated 2019 August; cited 2020 March 15]. Available from: https://www. pharmgkb.org/guidelineAnnotation/PA166104991.

56. Thailand, Ministry of Public Health, Department of Disease Control. Thailand national guidelines on HIV/AIDS treatment and prevention 2017. Bangkok: The Agricultural Cooperative Federation of Thailand; 2017.

57. Khanna D, Fitzgerald JD, Khanna PP, Bae S, Singh MK, Neogi T, et al. American College of Rheumatology guidelines for management of gout. Part 1: systematic nonpharmacologic and pharmacologic therapeutic approaches to hyperuricemia. Arthritis Care Res (Hoboken). 2012; 64(10): 1431-1446. doi: 10.1002/acr.21772.

58. Hershfield MS, Callaghan JT, Tassaneeyakul W, Mushiroda T, Thorn CF, Klein TE, et al. Clinical Pharmacogenetics Implementation Consortium guidelines for human leukocyte antigen-B genotype and allopurinol dosing. Clin Pharmacol Ther. 2013; 93(2): 153-158. doi: 10.1038/clpt. 2012.209.

59. Saokaew S, Tassaneeyakul W, Maenthaisong R, Chaiyakunapruk N Cost-effectiveness analysis of HLA-B*5801 testing in preventing allopurinol-induced SJS/TEN in Thai population. PLoS One. 2014; 9(4): e94294. doi: 10.1371/journal.pone.0094294.

60. Relling MV, Schwab M, Whirl-Carrillo M, Suarez-Kurtz G, Pui CH, Stein CM, et al. Clinical pharmacogenetics implementation consortium guideline for thiopurine dosing based on TPMT and NUDT15 genotypes: 2018 update. Clin Pharmacol Ther. 2019; 105(5): 1095-1105. doi: 10.1002/ cpt.1304.

61. The Royal Dutch Pharmacists Association. Annotation of DPWG guideline for azathioprine and TPMT. [updated 2019 August; cited 2020 March 15]. Available from: https://www.pharmgkb.org/ guidelineAnnotation/PA166104934.

62. National Comprehensive Cancer Network [NCCN]. NCCN clinical practice guidelines in oncology (NCCN Guidelines): colon cancer. Plymouth Meeting, PA: NCCN; 2020.

63. The Royal Dutch Pharmacists Association. Annotation of DPWG guideline for irinotecan and UGT1A1. [updated 2018 November; cited 2020 March 15]. Available from: https://www. pharmgkb.org/guidelineAnnotation/PA166104951.

64. Levine GN, Bates ER, Blankenship JC, Bailey SR, Bittl JA, Cercek B, et al. ACCF/AHA/SCAI guideline for percutaneous coronary intervention: a report of the American College of Cardiology foundation/American heart association task force on practice guidelines and the society for cardiovascular Angiography and Interventions. Circulation. 2011; 124(23): e574-651. doi: 10.1161/ CIR.0b013e31823ba622.

65. Fihn SD, Gardin JM, Abrams J, Berra K, Blankenship JC, Dallas AP, et al. ACCF/AHA/ACP/ AATS/PCNA/SCAI/STS guideline for the diagnosis and management of patients with stable ischemic heart disease: a report of the American College of Cardiology foundation/American Heart association task force on practice guidelines, and the American College of Physicians, American association for thoracic surgery, preventive cardiovascular nurses association, society for cardiovascular Angiography and Interventions, and society of thoracic surgeons. J Am Coll Cardiol. 2012; 60(24): e44-e164. doi: 10.1016/j.jacc.2012.07.013. 
66. Scott SA, Sangkuhl K, Stein CM, Hulot JS, Mega JL, Roden DM, et al. Clinical Pharmacogenetics Implementation Consortium guidelines for CYP2C19 genotype and clopidogrel therapy: 2013 update. Clin Pharmacol Ther. 2013; 94(3): 317-323. doi: 10.1038/clpt.2013.105.

67. The Royal Dutch Pharmacists Association. Annotation of DPWG guideline for clopidogrel and CYP2C19. [updated 2018 November; cited 2020 March 15]. Available from: https://www. pharmgkb.org/guidelineAnnotation/PA166104956.

68. The Heart Association of Thailand under the Royal Patronage of H.M. the King. Guideline for patients receiving oral anticoagulation therapy. [cited 2020 January 18]. Available from: http:// www.thaiheart.org/images/column_1291454908/warfarin_Guideline.pdf.

69. Johnson JA, Caudle KE, Gong L, Whirl-Carrillo M, Stein CM, Scott SA, et al. Clinical Pharmacogenetics Implementation Consortium (CPIC) guideline for pharmacogenetics-guided warfarin dosing: 2017 update. Clin Pharmacol Ther. 2017; 102(3): 397-404. doi: 10.1002/cpt.668.

70. The Royal Dutch Pharmacists Association. Annotation of DPWG guideline for warfarin and CYP2C9. [updated 2018 November; cited 2020 March 15]. Available from: https://www.pharmgkb. org/guidelineAnnotation/PA166182842.

71. Shaw K, Amstutz U, Kim RB, Lesko LJ, Turgeon J, Michaud V, et al. Clinical practice recommendations on genetic testing of CYP2C9 and VKORC1 variants in warfarin therapy. Ther Drug Monit. 2015; 37(4): 428-436. doi: 10.1097/FTD.0000000000000192.

72. Chong HY, Saokaew S, Dumrongprat K, Permsuwan U, Wu DB, Sritara P, et al. Cost-effectiveness analysis of pharmacogenetic-guided warfarin dosing in Thailand. Thromb Res. 2014; 134(6): 1278-1284. doi: 10.1016/j.thromres.2014.10.006.

73. The Royal Dutch Pharmacists Association. Annotation of DPWG guideline for warfarin and VKORC1. [updated 2018 November; cited 2020 March 15]. Available from: https://www. pharmgkb.org/guidelineAnnotation/PA166182841.

74. Goetz MP, Sangkuhl K, Guchelaar HJ, Schwab M, Province M, Whirl-Carrillo M, et al. Clinical pharmacogenetics implementation consortium (CPIC) guideline for CYP2D6 and tamoxifen therapy. Clin Pharmacol Ther. 2018; 103(5): 770-777. doi: 10.1002/cpt.1007.

75. The Royal Dutch Pharmacists Association. Annotation of DPWG guideline for tamoxifen and CYP2D6. [updated 2018 November; cited 2020 March 15]. Available from: https://www.pharmgkb. org/guidelineAnnotation/PA166104966.

76. Drogemoller BI, Wright GEB, Shih J, Monzon JG, Gelmon KA, Ross CJD, et al. CYP2D6 as a treatment decision aid for ER-positive non-metastatic breast cancer patients: a systematic review with accompanying clinical practice guidelines. Breast Cancer Res Tr. 2019; 173(3): 521-532. doi: 10.1007/s10549-018-5027-0.

77. National Comprehensive Cancer Network [NCCN]. NCCN clinical practice guidelines in oncology (NCCN Guidelines): breast cancer risk reduction. Plymouth Meeting, PA: NCCN; 2018.

78. Paluch-Shimon S, Cardoso F, Sessa C, Balmana J, Cardoso MJ, Gilbert F, et al. Prevention and screening in BRCA mutation carriers and other breast/ovarian hereditary cancer syndromes: ESMO Clinical Practice Guidelines for cancer prevention and screening. Ann Oncol. 2016; 27(Suppl.5): v103-110. doi: 10.1093/annonc/mdw327.

79. Tassaneeyakul W, Tiamkao S, Jantararoungtong T, Chen P, Lin SY, Chen WH, et al. Association between HLA-B*1502 and carbamazepine-induced severe cutaneous adverse drug reactions in a Thai population. Epilepsia. 2010; 51(5): 926-930. doi: 10.1111/j.1528-1167.2010.02533.x.

80. Sakolsatayadorn P. Announcement of national health security board types and limits of health service (No.13) B.E. 2561 (A.D. 2018). Thai Government Gazette No.135; 2018.

81. Yutthawong Y. Notification of the national drug system development committee national list of essential medicines B.E. 2558 (A.D. 2015). Thai Government Gazette No.132; 2015.

82. Pipatanasai N. Notification of the national drug system development committee national list of essential medicines B.E.2559 (A.D.2016). Thai Government Gazette No.133; 2016. 
83. Zhang H, Zhang T, Zhao H, Han N, Zhou H, He Y, et al. Low prevalence of human leukocyte antigen-B*5701 in HIV-1-infected Chinese subjects: a prospective epidemiological investigation. AIDS Res Ther. 2015; 12: 28. doi: 10.1186/s12981-015-0064-9.

84. Puthanakit T, Bunupuradah T, Kosalaraksa P, Vibol U, Hansudewechakul R, Ubolyam S, et al. Prevalence of human leukocyte antigen-B*5701 among HIV-infected children in Thailand and Cambodia: implications for abacavir use. Pediatr Infect Dis J. 2013; 32(3): 252-253. doi: 10.1097/ INF.0b013e3182745dba.

85. National Breast Cancer Foundation. What to do if you've tested positive. [cited 2020 March 19]. Available from: https://www.nationalbreastcancer.org/what-to-do-if-youve-tested-positive.

86. Rhiem K, Schmutzler R. Impact of prophylactic mastectomy in BRCA1/2 mutation carriers. Breast Care. 2014; 9(6): 385-389. doi: 10.1159/000369592.

87. Kauff ND, Scheuer L, Robson ME, Glogowski E, Kelly B, Barakat R, et al. Insurance reimbursement for risk-reducing mastectomy and oophorectomy in women with BRCA1 or BRCA2 mutations. Genet Med. 2001; 3(6): 422-425. doi: 10.1097/00125817-200111000-00008.

\section{Corresponding author}

Puree Anantachoti can be contacted at: puree.a@chula.ac.th

For instructions on how to order reprints of this article, please visit our website: 